\title{
A PATCH FOR VENTRICULAR SEPTAL DEFECTS DESIGNED TO AVOID HEART BLOCK
}

\author{
BY \\ P. R. ALLISON \\ From the Nuffield Department of Surgery, Oxford \\ Received February 28, 1962
}

Heart block after open operation on the right side of the heart is particularly serious when the right ventricle is already taxed to its limit by other loads. An incision in the anterior wall of the ventricle itself causes some disability. Closure of a ventricular septal defect in the presence of pulmonary hypertension may throw an added severe strain on the myocardium. Pulmonary regurgitation after division of a stenosed pulmonary valve, or pulmonary stenosis remaining after incomplete division of the valve may do likewise. Cine-radiographic studies show that complete heart block allows considerable regurgitation to take place through the tricuspid orifice, and in the presence of any of the above abnormalities this is likely to prove fatal. Such hazards have made most cardiac surgeons search for a means of closing a ventricular septal defect without injury to the bundle of His. The area in which the bundle is in danger is in the lower edge of the septal defect in that part of the septum between the tricuspid valve itself and the origin of that tendinous cord of the tricuspid valve that arises from the top of the septum (Fig. 1). This is the part of the defect that is furthest away from the surgeon who approaches a ventricular septal defect through the outflow tract of the right ventricle: it is partly concealed by the chordæ tendineæ. It is not always easy to be certain where the tendinous ring of the aorta joins the upper rim of the septum. The bundle can only be avoided with certainty by not stitching in this area, or stitching so timidly that part of the defect is not properly closed. The efficiency of any method must be assessed not only by the avoidance of heart block but also by the completeness of the closure.

In a search for a method of closing the defect without the necessity of placing stitches through this vulnerable part of the

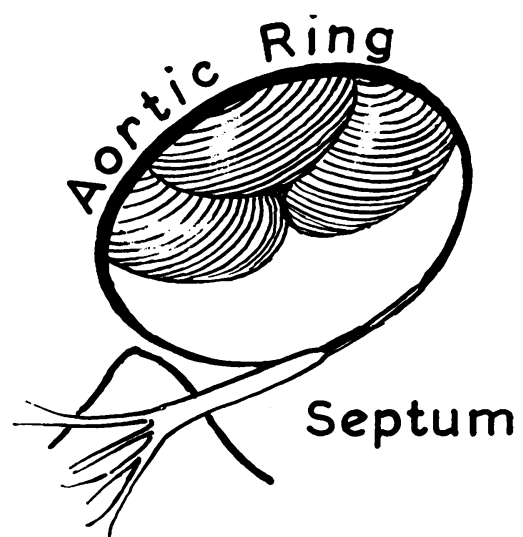

FIG. 1.-Diagram of ventricular septal defect showing the tendinous cord of the tricuspid valve arising from the top of the septum and marking the rim zone in which the conducting bundle is in danger. septum a lesson was taken from the way in which the foramen ovale was naturally closed or left as a probe-patent valve. A patch was devised, which, folded double upon itself, resembled the silhouette of a man's jacket on a clothes line (Fig. 2a and b). The method can in fact best be described by such an analogy. If a man's jacket is slung over a clothes-line so that the line goes evenly down the middle of the back where the man's spine would be, the two arms will hang below the front edges of the jacket where it is normally buttoned up. If now the caudal edges of the jacket are sewn together from the clothes-line above, down, and round the front edges where the buttons are, and if this continues up to about the middle button on a three button jacket, a patch is 


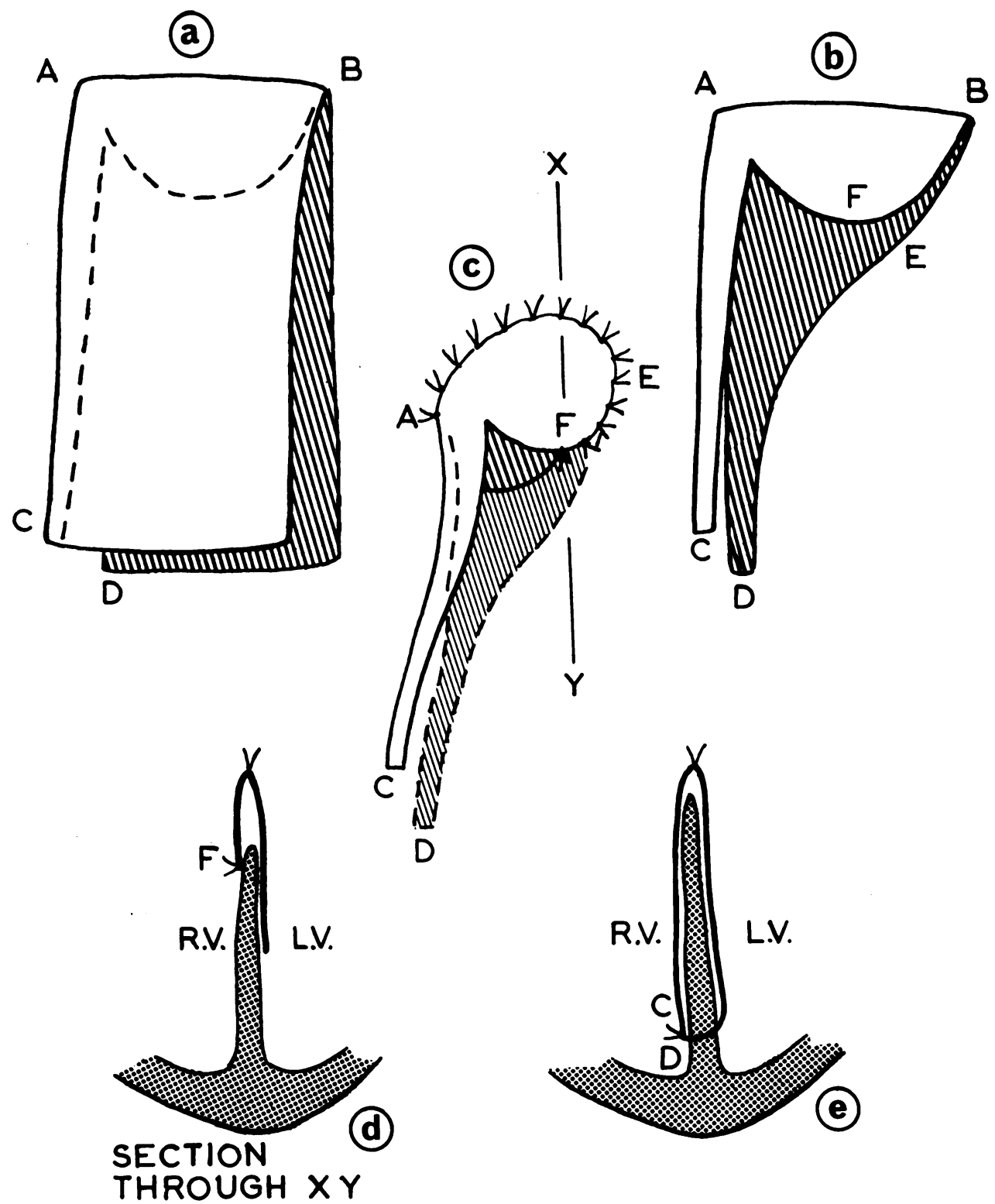

FIG. 2.-(a) and (b) The construction of the patch. (c) Diagram of the patch sutured to fill in a ventricular septal defect, $\mathrm{F}$ marking the point at which the tendinous cord of the tricuspid valve takes origin. (d) A section through $\mathrm{XY}$ in (c) shows how the broad flap in the left ventricle is apposed to the septum by the pressure in the left ventricle. (e) Shows how the arms of the patch are joined together in the right ventricle after the left arm has pierced the septum low down.

formed which, with a little tailoring, represents what has been used to close a ventricular septal defect. The edge represented by the clothes-line is sutured to the aortic ring at the top of the defect: the sutured edges of the jacket are stitched by deep biting stitches to the muscular rim of the septum on the surgeon's side of the attachment of the tendinous cord of the tricuspid valve where suturing is safe. The two "sleeves" of the jacket and the unsutured part of the breast area of the jacket hang 
down into the ventricular chambers, the anterior one into the right ventricle and the posterior one into the left. The simile of the jacket is not quite accurate because the "sleeves" of the patch are flaps and not tubes, and furthermore they come off the anterior edge and not from the "shoulders" of the jacket. The flap in the left ventricle is kept broad so that it covers a considerable area of the left ventricular side of the septum. This area is free from papillary muscles or chordæ tendineæ. The septal surface of the right ventricle, however, is covered with chordæ tendineæ and so the flap on this side is cut to follow the rim of the septal defect nearly to the tricuspid ring, whence the sleeve, coming off from the ascending rim of the patch at an acute angle, descends under the chordæ and parallel with the ring of the tricuspid valve (Fig. 2c). No sutures are placed in the septum deep to the tendinous cord that marks the danger zone. The "wrist" end of the left ventricular sleeve of

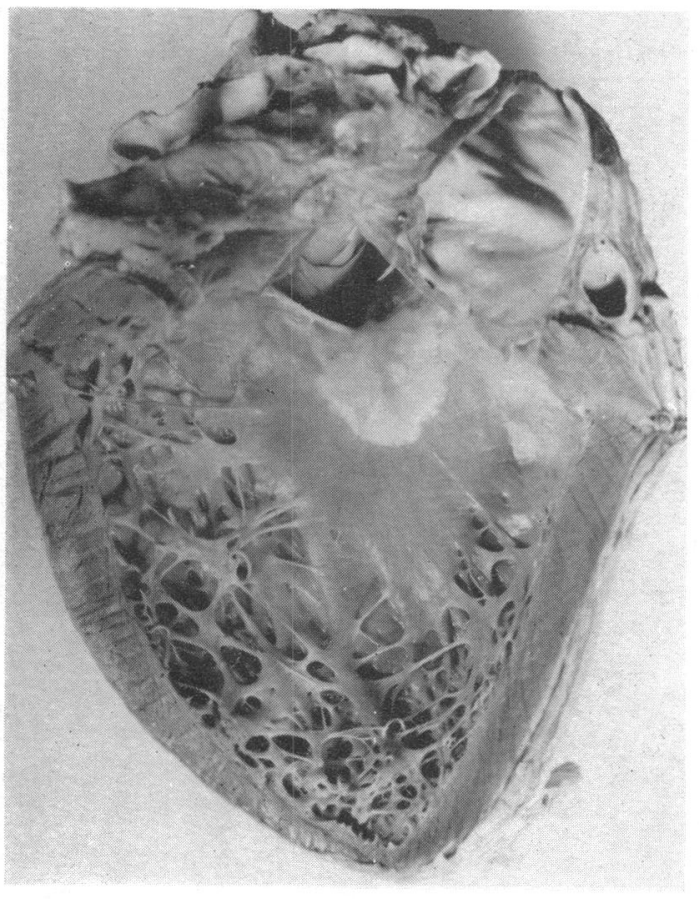

A

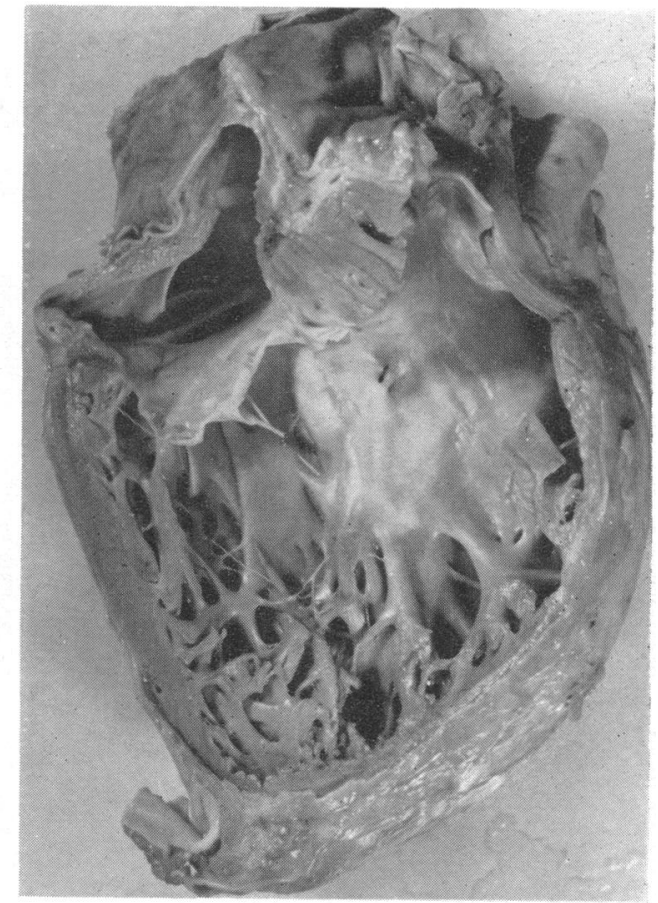

B

FIG. 3.-Autopsy specimen four months after insertion of patch. (A) left ventricular aspect with outflow tract incised to show continuity with aorta, and (B) right ventricular aspect where a black silk stitch is the only visible evidence of the patch.

the patch is fixed in the following way. It is tied to a silk thread on a large Moynihan's abdominal round-bodied needle. This needle is passed from the right ventricle through the ventricular septal defect and is directed downward in the left ventricle toward the diaphragm in a plane parallel with that of the tricuspid ring so that the point pierces the septum and emerges back into the right ventricle in the lowest part of the septum. As the needle is withdrawn the silk comes with it and finally the sleeve also emerges through the septum into the right ventricle. The two sleeves are then sewn to one another at the wrists (Fig. 2e). In order to facilitate the passage of the arm through the muscular ventricular septum the hole made by the needle may be enlarged with a tenotome. The double patch thus fills in the defect. It is meticulously sewn to the aortic ring and to the part of the septum that is free from danger (Fig. 2c). The danger area is closed by the broad sheet of the patch in the left ventricle which is anchored below by piercing the septum and being sewn to the other arm of 
the patch. The high pressure in the left ventricle is sufficient to keep it apposed to the septum (Fig. 2d), and there is a possibility, though this has not been ascertained, that if the pressure were to rise too high in the right ventricle in the immediate post-operative period, relief could be obtained by displacing the patch away from the opening, and causing a right-to-left leak in the same way as an increase in right atrial pressure may cause a leak through the valvular opening of the foramen ovale.

It has already been said that the junction of the aortic ring, the tricuspid ring, and the top edge of the septum may be difficult to define exactly. If the top of the septum is mistaken for part of the aortic ring and sutured to the patch, the bundle may be injured, and this did occur in one patient whose normal conduction was fortunately fully restored after a short time. The method is, therefore, not entirely free from risk, but it appears to diminish the risks of block very considerably and, at the same time, to be a dependable way of closing the septal defect completely.

One patient in whom this type of patch was used was suffering from a ventricular septal defect and increased pulmonary vascular resistance. There was uncertainty about the wisdom of closing the defect, but finally operation was performed and the patient recovered. Some months later, however, the pulmonary resistance having shown no tendency to fall, he died in heart failure. At necropsy the patch was found to be perfectly incorporated in the septum and covered with glistening endocardium (Fig. 3). On naked eye inspection it was not possible to discern the arms of the patch, but on palpation some thickening could be felt in the septum which corresponded to their position. This was the only specimen at necropsy, but post-operative catheterization, angiography, and dye studies on other patients have indicated that the septal defect has been satisfactorily closed.

\section{SUMMARY}

A patch made of "teflon" or "dacron" for closing ventricular septal defects is described. The virtue of this particular patch is that it is entirely effective without the need for any stitching or trauma to that part of the ventricular septum in which the conduction bundle lies. Both necropsy and post-operative catheter studies show that the patch becomes incorporated in the septum and that the healing is as firm in the area where no stitching is done as it is elsewhere. 